\title{
O gênero Collaea DC. (Leguminosae, Papilionoideae) na Região Sul do Brasil ${ }^{1}$
}

\author{
Guilherme Bordignon Ceolin² e Sílvia Teresinha Sfoggia Miotto ${ }^{3}$
}

Recebido em 8/11/2008. Aceito em 30/01/2009

RESUMO - (O gênero Collaea DC. (Leguminosae, Papilionoideae) na Região Sul do Brasil). Este trabalho apresenta os resultados do levantamento florístico e estudo taxonômico abrangendo o gênero Collaea na Região Sul do Brasil. Este gênero é exclusivamente sul-americano, possuindo seis ou sete espécies, distribuídas pelo Peru, Bolívia, Brasil, Paraguai e no norte e centro da Argentina. Para a Região Sul foram confirmadas três espécies: Collaea aschersoniana (Taub.) Burkart, C. speciosa (Loisel.) DC. e C. stenophylla (Hook. et Arn.) Benth. É apresentada uma chave para a identificação dos táxons estudados, além de ilustrações, descrições e dados ecológicos.

Palavras-chave: Collaea, Diocleinae, Fabaceae, florística

ABSTRACT - (The genus Collaea DC. (Leguminosae, Papilionoideae) in South Brazil). We carried out a floristic survey and taxonomic study of the genus Collaea DC. (Leguminosae, Papilionoideae) in South Brazil. This genus occurs exclusively in South America, including six or seven species found in Peru, Bolivia, Brazil, Paraguay, central and northern Argentina. In South Brazil, three species were confirmed: Collaea aschersoniana (Taub.) Burkart, C. speciosa (Loisel.) DC. and C. stenophylla (Hook. et Arn.) Benth. An identification key, descriptions and illustrations for all taxa are provided, as well as ecological and distribution data.

Key words: Collaea, Diocleinae, Fabaceae, floristics

\section{Introdução}

O gênero Collaea pertence à família Leguminosae, subfamília Papilionoideae e está incluído na tribo Phaseoleae, subtribo Diocleinae, juntamente com Canavalia DC., Camptosema Hook. et Arn., Cleobulia Mart. ex Benth., Cratylia Mart. ex Benth., Dioclea Kunth, e Galactia P. Browne (Lewis et al. 2005). Porém, a circunscrição do gênero até recentemente era confusa e variável entre os autores, que o consideravam como um sinônimo de Galactia.

Bentham (1859) e Grisebach (1874) consideraram Collaea separado de Galactia. Entretanto, Taubert (1894) reconheceu apenas Galactia, mantendo Collaea apenas como uma seção do mesmo. Burkart (1943) manteve a delimitação de Taubert (l.c.). Porém, em obras posteriores, reviu sua posição e passou a tratar os gêneros como distintos (Burkart 1952; 1971). Barroso (1991) voltou a considerar Collaea sinonímia de Galactia, argumentando que os caracteres utilizados por Burkart (1971) para separá-los eram inconsistentes e sobrepunham-se aos da seção Collearia do gênero Galactia, tornando confusa a delimitação das espécies. Queiroz et al. (2003), através de um estudo filogenético baseado em caracteres morfológicos, consideraram o gênero Collaea muito próximo de Galactia, porém, monofilético, independente e distinto.

Collaea é um gênero exclusivamente sul-americano, com cerca de seis ou sete espécies, ocorrentes no Peru, Bolívia, Paraguai, Brasil e no norte e centro da Argentina (Burkart 1987; Lewis et al. 2005). O Brasil pode ser considerado um centro de riqueza do gênero, pois registra a ocorrência de quatro espécies. Destas, algumas são restritas a certas regiões, como C. cipoensis $\mathrm{R}$. H. Fortunato, espécie com ocorrência conhecida até o momento somente para a Serra do Cipó, em Minas Gerais (Fortunato 1995).

Na Região Sul do Brasil, as leguminosas já foram objeto de estudo de diversos levantamentos florísticos e/ou tratamentos taxonômicos, sendo o Rio Grande do Sul o mais estudado, conforme dados compilados por Miotto (1993). Dentre estes se destacam os estudos florísticos e fitogeográficos de Rambo (1953; 1966).

A despeito do conhecimento destes táxons no Rio Grande do Sul, para os estados de Santa Catarina e do Paraná não há estudos taxonômicos ou florísticos abrangendo o gênero Collaea na sua atual circunscrição. Para Santa Catarina, pode ser mencionado o trabalho de Reitz (1961), que cita Galactia stenophylla Hook. et Arn. (sinônimo de Collaea stenophylla [Hook et Arn.] Benth.), e o de Klein (1979), que cita para o Vale do Itajaí a espécie Collaea aschersoniana (Taub.) Burk. Já para o Paraná, há um cheklist compilado por Angely (1965), que também considera Collaea na sinonímia de Galactia. Além destes, vários outros trabalhos florísticos mencionam em suas listas a ocorrência de espécies do gênero (Takeda \& Farago 2001; Hatschbach et al. 2005; von Linsingen et al. 2006; Cervi et al. 2007).

O objetivo deste trabalho é esclarecer, através do levantamento florístico e tratamento taxonômico, quais espécies de Collaea existem na Região Sul do Brasil, bem como identificar suas áreas de ocorrência e ambientes preferenciais.

\section{Material e métodos}

Para o Rio Grande do Sul, utilizou-se o trabalho de Miotto (1980), cujos dados, após revisão e atualização, serviram de base para as análises florísticas e taxonômicas no Estado. Para Santa Catarina e Paraná, foram realizadas viagens de coleta em 2006 e 2007, nos meses de primavera e

Parte da dissertação de Mestrado do primeiro Autor

2 Programa de Pós-Graduação em Botânica, Universidade Federal do Rio Grande do Sul, Porto Alegre, RS, Brasil. E-mail: guilherme_ceolin@yahoo.com.br (Autor para correspondência)

3 Professora Associada II, do Departamento de Botânica, Universidade Federal do Rio Grande do Sul, Porto Alegre, RS, Brasil 
verão, por serem épocas coincidentes com a floração e a frutificação dos espécimes de Collaea. O complemento dos dados deu-se através da análise e identificação de exsicatas depositadas em herbários nacionais e estrangeiros. As siglas dos herbários indexados seguem Holmgren \& Holmgren (2007): CTES, F, FLOR, FUEL, HAS, HB, HBR, ICN, MBM, PACA, PEL, SP. Além destes, também foi revisado o herbário da Universidade de Caxias do Sul, cuja sigla não oficial é HUCS.

O material coletado foi herborizado e incorporado ao herbário do Instituto de Biociências da Universidade Federal do Rio Grande do Sul (ICN). As identificações foram feitas com base em literatura específica para o grupo e confirmadas através de descrições originais, tipos nomenclaturais ou fotografias de tipos, além de comparações com exsicatas de herbários.

A chave de identificação para as espécies de Collaea para a Região Sul do Brasil foi elaborada a partir da análise das estruturas vegetativas e reprodutivas dos materiais examinados e os hábitos foram ilustrados a partir de fotocópia de exsicatas. Para a ilustração das peças florais, as flores retiradas das exsicatas foram reidratadas e desenhadas com o auxílio de câmara-clara.

Os dados sobre as localidades e os tipos de ambiente onde as espécies de Collaea são encontradas foram obtidos através de observações pessoais em viagens de coleta, das informações constantes na bibliografia e nas fichas das exsicatas.

\section{Resultados e discussão}

Collaea DC., Annales des Sciences Naturelles 4: 96. 1825

Espécie tipo: Collaea speciosa (Loisel.) DC.

Subarbustos a arbustos, às vezes superiores a $3 \mathrm{~m}$ alt., eretos a ligeiramente curvados no ápice. Folhas digitado-trifolioladas, pecioladas, subsésseis ou sésseis, folíolos subiguais ou o central um pouco maior. Estípulas e estipelas caducas, raramente presentes. Inflorescências axilares a terminais, racemosas a umbeliformes, sésseis, subsésseis a pedunculadas. Brácteas e bractéolas amplas. Cálice campanulado, 4-laciniado devido à fusão das duas sépalas vexilares, pubescente a tomentoso, com tricomas seríceos, vilosos, velutinos a lanosos. Corola geralmente vistosa, vermelha, violácea, azulada, branca e matizes destas cores. Estandarte reflexo, glabro a pubescente no ápice, bicaloso na base. Alas e peças da carena glabras a pubescentes. Androceu 10-estaminado, pseudomonadelfo. Ovário linear, reto a falcado, séssil, com disco nectarífero na base, pubescente a tomentoso. Estilete geralmente glabro. Estigma apical, globoso. Legume linear, comprimido, com deiscência elástica, plurisseminado, pubescente, seríceo, tomentoso, velutino a viloso.

Dentre os gêneros de Leguminosae nativos da Região Sul do Brasil, poucos são os que apresentam o cálice 4-laciniado em todas as espécies, o que facilita consideravelmente a identificação na categoria genérica, pois restringe o universo amostral a algumas poucas possibilidades.

Na subtribo Diocleinae, apenas Galactia, Collaea e Camptosema apresentam esta característica invariável em todas as espécies, sendo que nos outros gêneros há graus variados de soldadura do lacínio vexilar. Porém, os três podem ser diferenciados entre si devido à presença de ovário estipitado e flores sempre vermelhas em Camptosema, características ausentes em Galactia. Apesar de algumas espécies de Collaea apresentarem flores vermelhas, o mesmo se distingue de Camptosema por possuir o ovário séssil, as folhas digitado-trifolioladas e o cálice campanulado, ao contrário das folhas pinado-trifolioladas ou unifolioladas e do cálice tubuloso em Camptosema. Por sua vez, os gêneros Galactia e Collaea podem ser diferenciados, principalmente, pelo hábito: em Galactia geralmente herbáceo, prostrado a volúvel, poucas vezes ereto e, neste caso, raramente passando de $1,5 \mathrm{~m}$ de altura. Além disso, Collaea não possui os racemos nodosos como os de Galactia.

Para a Região Sul do Brasil foram confirmadas três espécies de Collaea, que podem ser diferenciadas através das características apresentadas na chave abaixo:

\section{Chave para as espécies de Collaea ocorrentes na Região Sul do Brasil}

1. Inflorescências em racemo alongado; corola vermelha, coccínea a purpúrea........ 2. C. speciosa

1. Inflorescências corimbiformes ou umbeliformes; corola azulada, violácea, róseoazulada até branca.

2. Folhas sésseis; estandarte flabeliforme. 3. C. stenophylla

2. Folhas pecioladas; estandarte orbicular a oblongo-orbicular. 1. C. aschersoniana

1. Collaea aschersoniana (Taub.) Burkart, Legum. Argent. (ed. 2): 545. 1952.

Galactia aschersoniana Taub., Flora 72: 427. 1889. Tipo: Brasilia austro-orientale, loco non indicato, Sellow 152 (Holótipo B, destruído; fotografia do Holótipo F!).

Fig. 1-7

Subarbustos eretos, até $1,5 \mathrm{~m}$ alt. Caule ramificado ou não, sublenhoso, cilíndrico, estriado, com lenticelas, pubescência adpressa, serícea, canescente, tricomas curtos. Folhas digitado-trifolioladas, pecíolo curto 1-2 mm compr., piloso; folíolos rígidos, coriáceos, estreitos, o apical medindo 28-48(63) x 5-9 mm e os basais 25-45(56) x 4-7(8) $\mathrm{mm}$, oblongos a oblongo-lanceolados; ápice obtuso a truncado, curto-mucronado, às vezes emarginado; base arredondada a aguda, às vezes revoluta na inserção dos peciólulos; face adaxial glabra, com nervuras marcadas, conspícuas; face abaxial tomentosa, tricomas adpressos, seríceos, amarelados. Estípulas caducas, não vistas. Inflorescências axilares, umbeliformes, plurifloras, sésseis, pedicelos (4)6-9(10) mm compr., vilosos, canescentes. Brácteas orbiculares, 2-4(6) mm compr., seríceas. Bractéolas 6-10 mm compr., com ápice acuminado, seríceas, canescentes. Cálice campanulado, com 4 lacínios subiguais em comprimento, (5)6-8 x 8-10 $\mathrm{mm}$, cimbiformes a lanceolados, com ápice agudo, apiculado; tricomas seríceos, canescentes a marrons. Corola branca. Estandarte orbicular a oblongo-orbicular, 10(17) x 10(17) mm, glabro, ungüícula curta, com menos de $1 \mathrm{~mm}$ compr., ápice arredondado a profundamente emarginado, aurículas inflexas na base. Alas 8-10 x 4-6 mm, ápice arredondado a obtuso. Peças da carena 7-10 x 3-5 mm, 
falciformes, ápice truncado. Ovário reto, pubescente, tricomas seríceos a vilosos, canescentes a amarelados. Estilete menor que o comprimento do ovário. Estigma levemente globoso. Legume 28 x $5 \mathrm{~mm}$, achatado lateralmente, ápice caudado, tomentoso, com tricomas grisáceos a marrons. Sementes não vistas.

Material selecionado: BRASIL. Paraná: Castro, estrada Cerne, rio Cunhaporanga, 14/X/1968, fl., G. Hatschbach 20072 (HB, MBM). Piraquara, Jardim Holandês, 01/X/1997, fl., J. M. Silva et al s.n. (PEL19892). Ponta Grossa, Vila Velha, sem data, fl.fr., I. J. M. Takeda s.n. (MBM307210). São José dos Pinhais, rodovia Governador Lupion, rio Pequeno, 3/IX/1961, fl., G. Hatschbach s.n. (HB15806). São Mateus do Sul, rodovia BR-163, rio Potinga, 16/IX/1988, fl., G. Hatschbach 52137 \& J. M. Silva (FLOR, MBM).

Espécie bastante rara na Região Sul, não tendo sido encontrada em nenhuma viagem de coleta. Suspeita-se que esteja localmente extinta ou muitíssimo ameaçada, pois não existe registro de coleta nos últimos dez anos. Aparentemente restrita ao Estado do Paraná, não havendo informações de sua ocorrência em outras regiões do Brasil. O período de floração é entre setembro e outubro. Pouco se sabe em relação ao período de frutificação e à forma dos frutos, pois também Taubert (1889), no protólogo da espécie, referiu-se ao fruto como "Legumen ignotum". Apenas uma exsicata foi examinada contendo esta estru-

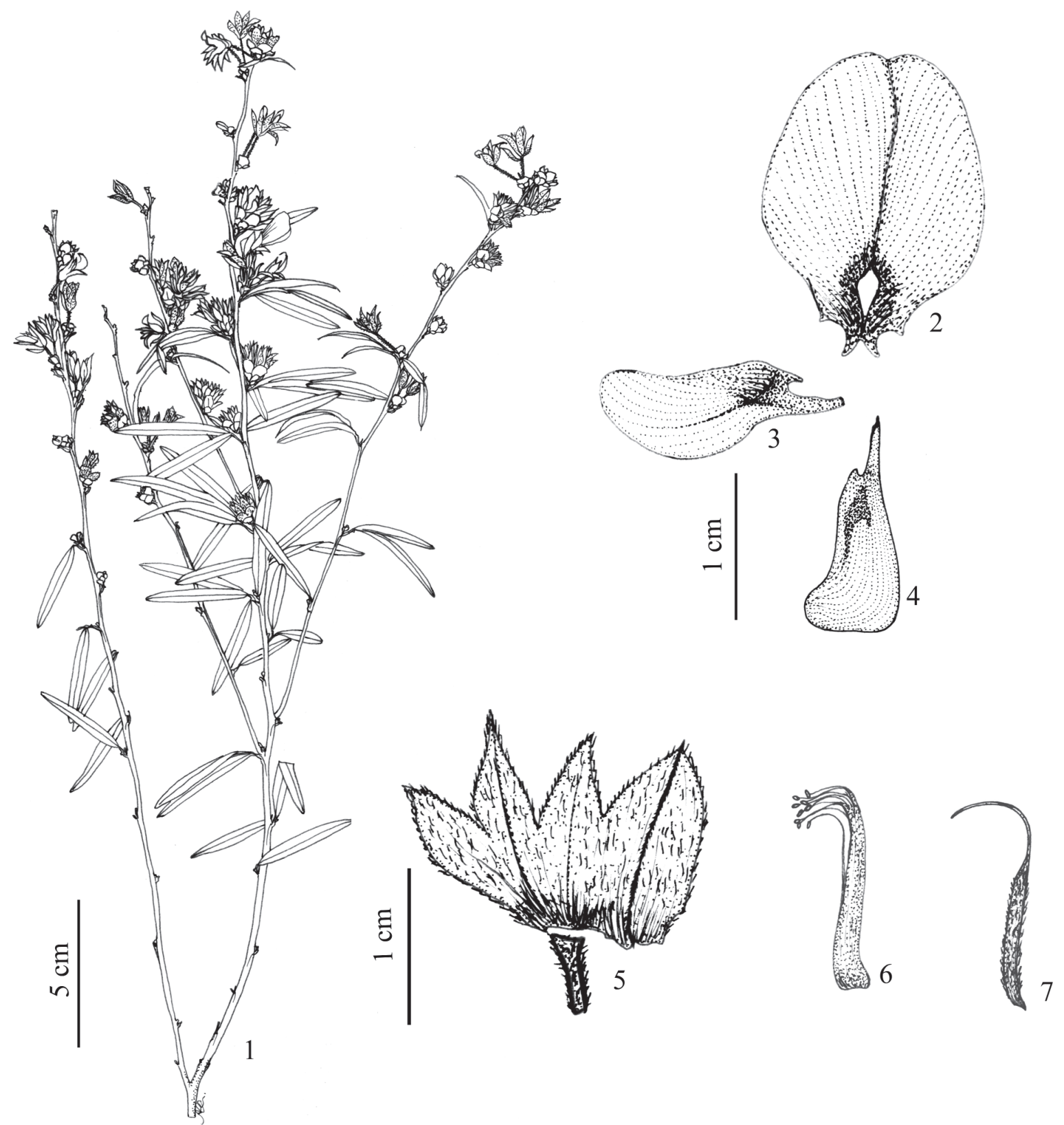

Figuras 1-7. Collaea aschersoniana: 1) Ramo. 2) Estandarte. 3) Ala. 4) Peça da carena. 5) Cálice com pedicelo. 6) Androceu. 7) Gineceu. 
tura, a qual foi descrita no presente trabalho de maneira incompleta, pois além de o fruto estar imaturo, tornando inviável a descrição das sementes, não havia data de coleta, o que não permitiu a indicação da época de frutificação. Segundo as anotações de exsicatas feitas pelos coletores, C. aschersoniana é encontrada em brejos ou muito próxima de lugares úmidos.

2. Collaea speciosa (Loisel.) DC., Mem. Legum. 6: 245. 1825.

Cytisus speciosus Loisel., Traité des Arbres et Arbustes 25:160.1812.

Galactia speciosa (Loisel.) Britton, Bull. Torrey Club 16: 262. 1889.

Fig. $8-18$

Arbustos eretos, ramificados, podendo atingir mais de $3 \mathrm{~m}$ alt. Caule lenhoso, cilíndrico, estriado a canelado ao longo de toda extensão, às vezes com lenticelas, glabro na base com pubescência aumentando gradativamente em direção ao ápice; indumento denso, adpresso, viloso, velutino ou seríceo com tricomas castanho-claros, dourados, grisáceos a canescentes próximo ao ápice. Folhas digitadotrifolioladas, às vezes com ráquis curta, até $4 \mathrm{~mm}$ compr.; pecíolos 2-10 mm compr., densamente pubescentes, com tricomas vilosos, castanhos a amarelados; peciólulos tomentosos; folíolos estreitos ou largo-elípticos, oblongos, oblongo-elípticos, oblongo-lanceolados a lanceolados, o apical 40-90(98) x (9)10-25(29) mm, os basais (32)37$81(85)$ x 7-24(27) mm; ápice agudo, arredondado, obtuso a truncado, às vezes curto-mucronado; base aguda, arredondada ou obtusa, muitas vezes assimétrica e revoluta na inserção do peciólulo; bordo às vezes ligeiramente revoluto; face adaxial glabra a finamente pubescente, opaca ou brilhante, verde-escura a verde-amarelada, nervuras impressas a inconspícuas; face abaxial densamente pilosa, indumento adpresso, seríceo a velutino, tricomas canescentes, grisáceos, amarelados, castanhos ou dourados, nervuras salientes, principalmente a central. Estípulas caducas, quando presentes ovadas a lanceoladas, estriadas e densamente pubescentes. Inflorescências axilares, do tipo racemo alongado, plurifloras, sésseis a pedunculadas; pedúnculo (6) 8-56(62) mm compr., estriado, densamente pubescente, indumento viloso a velutino, tricomas dourados, amarelados ou castanho-claros; pedicelos (1)2-15 mm compr., pubescentes, lanosos a velutinos, tricomas castanhos a dourados. Brácteas 9-12(15) mm compr, suborbiculares, cimbiformes a largo-lanceoladas, tomentosas, indumento seríceo a viloso, tricomas canescentes a dourados. Bractéolas lanceoladas, ápice agudo a obtuso, estriadas, seríceas a vilosas, com tricomas castanhos a dourados. Cálice campanulado, 10-15(16) x (14)15-18(20) mm, com 4 lacínios, os laterais lanceolados, com ápice agudo; o vexilar mais amplo, cimbiforme, ápice arredondado, base alargada; o carenal mais longo, até duas vezes maior que o tubo calicinal, ápice agudo; indumento denso, seríceo, viloso a velutino, tricomas castanho-escuros, dourados, grisáceos ou canescentes. Corola vermelha, coccínea a purpúrea, quase o dobro do comprimento do cálice. Estandarte pubescente a tomentoso no ápice, tricomas adpressos, seríceos, canescentes, 21-30(35) x (12)15-20 mm, orbicular a suborbicular, com ápice retuso a obcordado, ungüícula longa, 4-9 mm compr; base com calos e duas aurículas inflexas. Alas glabras a fracamente pubescentes na base, (21)22-30 x 6-10(11) mm, ápice arredondado, obtuso a levemente agudo, cuculadas. Peças da carena glabras a fracamente pubescentes, (20)21-33 x (5)6-10 mm, ápice truncado a obtuso, cuculadas. Ovário estreito, reto a levemente falcado, tricomas velutinos, dourados a canescentes. Estilete levemente alargado na base, levemente pubescente, igual comprimento do ovário. Estigma globoso. Legume 45-75 x 5-15 mm, ápice caudado, cálice decíduo na maturação, indumento seríceo, viloso a velutino, tricomas dourados, castanhos a marrons. Sementes 3,8-4,2 mm diâm., achatadas lateralmente, amareladas.

Material selecionado: BRASIL. Paraná: Campo Magro, Morro da Palha, 22/I/2002, fl., L. A. Valente et al. 3540 (HUCS). Cerro Azul, indo para Tunas do Paraná, BR-476, 25001'09,6”'S 4904'28,4”'W, 700 m, 9/I/2007, fl., G. B. Ceolin \& S. T. S. Miotto 2447 (ICN). Jaguariaíva, 29/IX/1992, fl., A. C. Cervi 3778 et al. (ICN). Mangueirinha, BR-449, km-22, $26^{\circ} 20^{\prime} 06,3^{\prime \prime S} 52^{\circ} 07^{\prime} 01,6^{\prime} \mathrm{W}, 18 / \mathrm{XII} / 2006$, fl. fr., $G$. B. Ceolin 114 et al. (ICN). Palmeira, indo para São Mateus do Sul 25³3'38,6”S 5007'22,8”W, 11/I/2007, fl., G. B. Ceolin 104 et al. (ICN). Teixeira Soares, Fazenda Capão Bonito, 02/X/1995, fl., M. C. Dias et al. 13 (FUEL). Santa

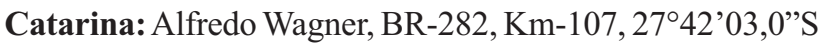
49²0'48,0”W, 29/XI/2006, fl.fr., G. B. Ceolin 093 et al. (ICN). Mafra, 750 m, 12/XII/1962, fl.fr., R. M. Klein s.n. (HBR45755). Timbó, represa do Rio Cedro, 650 m, 9/ VII/1956, fl., R. Reitz \& R. M. Klein 3513 (FLOR). Rio Grande do Sul: Nonoai, 20/IV/1959, fl., L. R. M. Baptista s.n. (ICN2220).

Espécie encontrada geralmente isolada, aparentemente não formando populações numerosas. É dada como extinta no Rio Grande do Sul, pois o último registro de sua ocorrência é de 1959. No Brasil, além da Região Sul, ocorre em São Paulo (Silvestre-Capellato \& Melhem 1997), Rio de Janeiro (Morim 2006), Minas Gerais (Araújo et al. 2002) e Bahia (Lewis 1987). É encontrada também no Peru e Bolívia (Fortunato 1995). Collaea speciosa é polinizada por beija-flores (Buzato et al. 2000), sendo, como um todo, bastante atrativa para a avifauna, pois, além do néctar, há relatos de que algumas aves da subfamília Thraupinae (saíras, sanhaços) removem o cálice para consumirem os estames (Manhães 2003). Floresce e frutifica simultaneamente a partir do mês de outubro até fevereiro, embora existam alguns registros de florações esporádicas nos meses de maio, julho e agosto. É encontrada tanto a pleno sol em áreas desabrigadas, como campos cerrados, campos pedre- 
gosos e beiras de estradas, quanto à sombra, em bordas de mato ou até mesmo em matas de galeria.

3. Collaea stenophylla (Hook et Arn.) Benth., Fl. bras. 15 (1B): 146. 1862.

Galactia stenophylla Hook et Arn., Bot. Misc. 3: 182. 1833. Collaea virgata Benth., F1. Bras. 15 (1B): 146. 1862.

Fig. 19-28
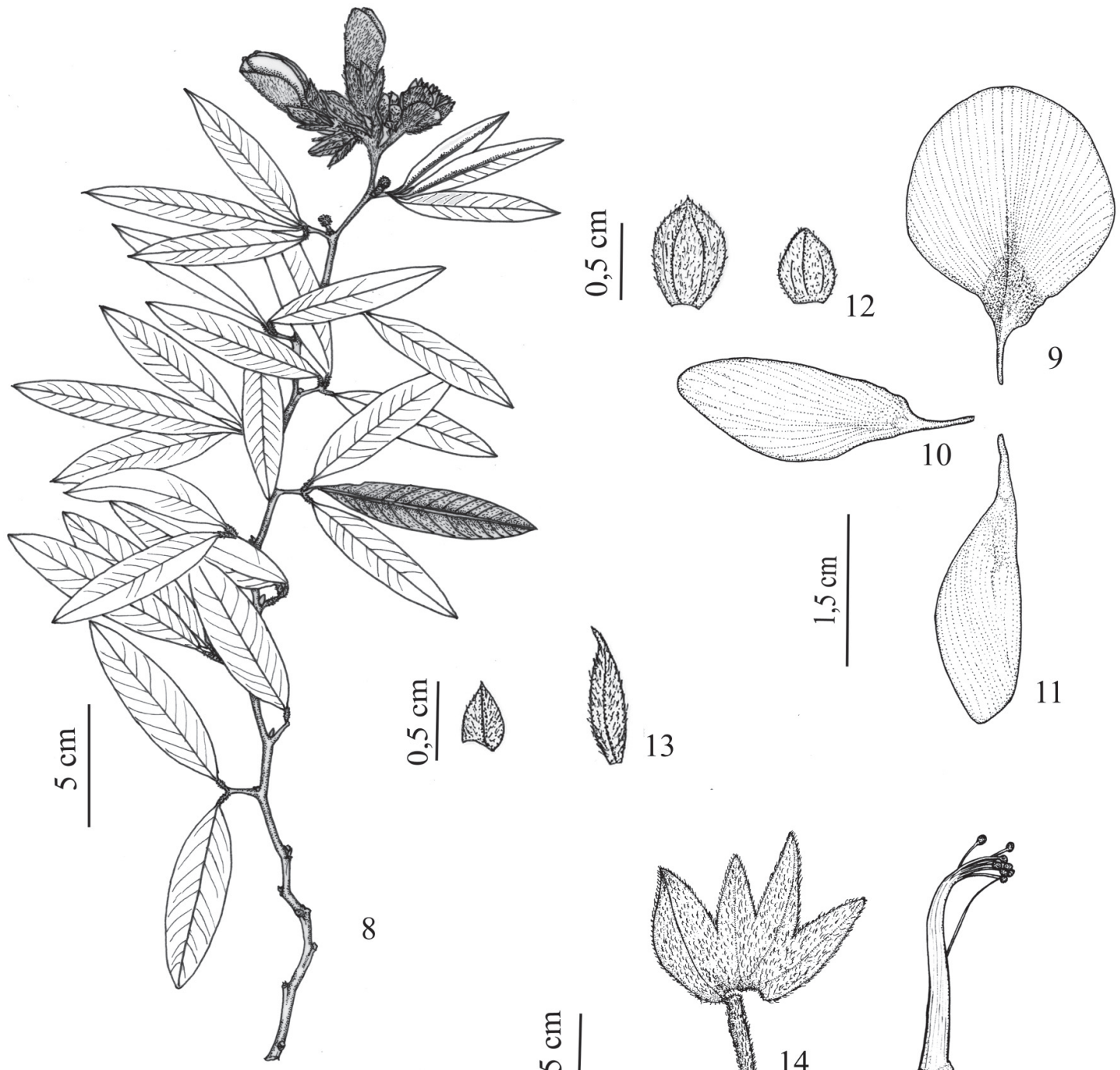

13
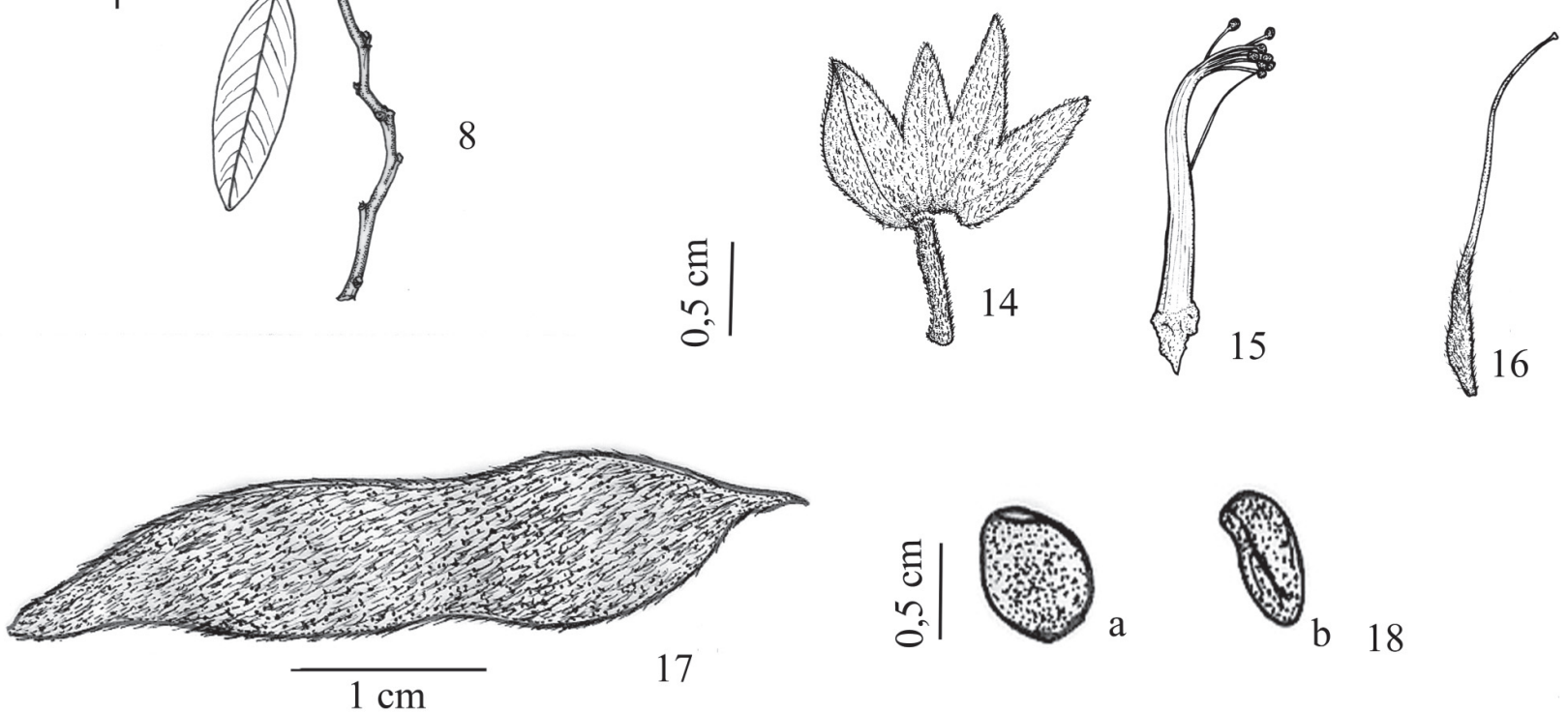

b 18 
oblongos, oblongo-lanceolados, oblongo-elípticos, estreitoelípticos, estreito-lanceolados a lanceolados, o apical entre (40)44-84(86) x (3)4-11 mm, os basais entre (30)32-75(78) x 3-12(19) mm; ápice arredondado, obtuso ou truncado, às vezes curto-mucronado; base aguda, atenuada ou cuneada, podendo ser ligeiramente revoluta na inserção do peciólulo; face abaxial glabra ou com pilosidade adpressa, serícea, tricomas alvos, nervura principal saliente, podendo ter pilosidade vilosa; as demais nervuras podem ser fraca a densamente reticuladas até buladas; face adaxial glabra a fracamente serícea, tricomas curtos, adpressos, nervuras impressas, a central formando sulco; nervura marginal às vezes evidente. Estípulas caducas, podendo estar presentes nos ramos jovens, deltóides, com ápice agudo-apiculado,

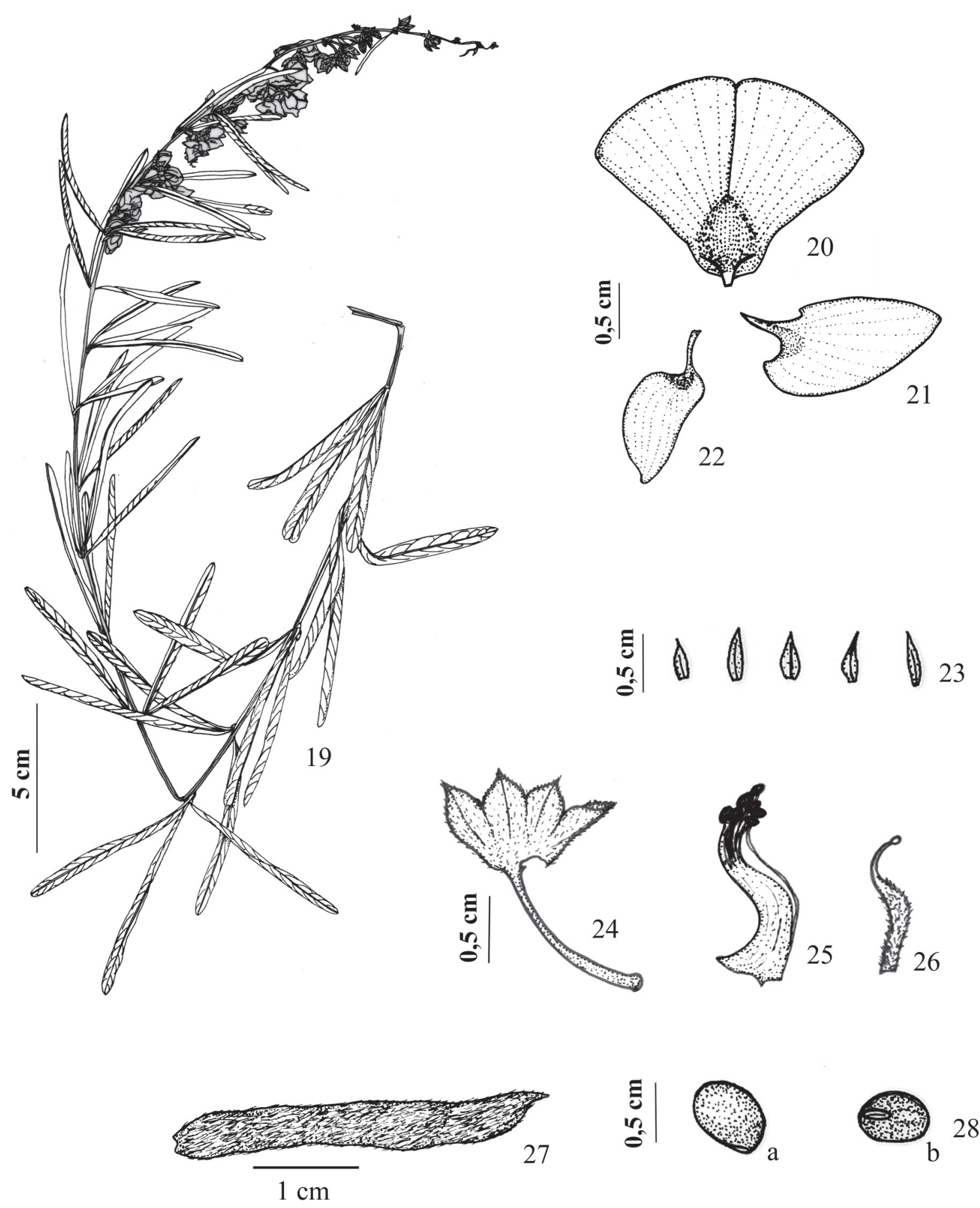

Figuras 19-28. Collaea stenophylla: 19) Ramo. 20) Estandarte. 21) Ala. 22) Peça da carena. 23) Bractéolas. 24) Cálice com pedicelo. 25) Androceu. 26) Gineceu. 27) Fruto. 28) Sementes. A) vista frontal; b) vista lateral. 
pilosas, canescentes. Inflorescências axilares, corimbiformes ou umbeliformes, plurifloras; pedicelos densamente pubescentes, seríceos a vilosos, canescentes, $(4,5) 6-11(13)$ mm compr. Brácteas 1-3 mm compr., deltóides, vilosas, tricomas castanhos a canescentes, ápice agudo, mucronado. Bractéolas 2-4,5 mm compr., rombiformes a lanceoladas, pubescentes. Cálice campanulado, com 4-7(11) x 5-12(13) $\mathrm{mm}$, 4-laciniado, o lacínio vexilar mais largo, cimbiforme, com ápice truncado a retuso, o carenal pouco mais longo, ápice agudo, os laterais subiguais entre si; todos densamente pilosos, seríceos a lanosos, tricomas canescentes a castanhos. Corola azulada, violácea, róseo-azulada até branca. Estandarte glabro a esparsamente pubescente no ápice, flabeliforme, $(9,5) 10-15(16) \times(11) 12-18(20) \mathrm{mm}$, ápice arredondado a emarginado, ungüícula muito curta, com menos de $1 \mathrm{~mm}$ compr., base com calos, geralmente, com duas aurículas inflexas. Alas cuculadas, 10-16(17) x 4-8 mm, glabras ou esparsamente pilosas, ápice arredondado ou agudo. Peças da carena cuculadas, 8-16(18) x 3-5(6) mm, glabras, ápice truncado ou obtuso. Ovário falcado, tomentoso, indumento seríceo a viloso, tricomas alvos, cobrindo quase todo o estilete. Estilete alargado na base, quase metade do comprimento do ovário. Estigma globoso. Legume comprimido lateralmente, reto a ligeiramente falcado, (26)30-65 x 4-5 mm de comprimento, tomentoso, indumento seríceo, velutino a viloso, tricomas canescentes, ápice caudado, cálice persistente na base. Sementes 4-5 mm diâm., elipsóides, globosas, negras a marrom-avermelhadas.

Material selecionado: BRASIL. Paraná: Castro, estrada do Cerne, Rio Cunhaporã, 14/X/1968, fl., G. Hatschbach 20072 (HB). Mangueirinha, BR-449, Km22, 26²0'06,3”S 5207'01,6”W, 18/XII/2006, fl., G. B. Ceolin 111 (ICN). Palmas, em direção a Mangueirinha, $26^{\circ} 21^{\prime} 40,4^{\prime \prime} \mathrm{S} 52^{\circ} 06^{\prime} 04,0^{\prime \prime} \mathrm{W}, 18 / \mathrm{XII} / 2006$, fl.fr., G. B. Ceolin 121 (ICN). Ponta Grossa, Parque de Vila Velha, 18/X/1961, fl., G. Pabst 5958 \& E. Pereira 6131 (HB). Santa Catarina: Campos Novos, BR-282, 2721'30,0”S $51^{\circ} 19^{\prime} 27,0$ ”'W, 1263 m, 10/X/2006, fl., G. B. Ceolin 051 et al. (ICN). Capão Alto, BR-116, Km-274, 2759'02,2”S 50³1'04,6”W, 11/X/2006, fl., G. B. Ceolin 061 et al. (ICN). Capinzal, entrada da cidade, 13/IX/1963, fl., $R$. Reitz \& R. M. Klein 16197 (HBR, FLOR). Lages, indo para Capão Alto, BR-116, cerca de $20 \mathrm{~m}$ antes da ponte sobre o

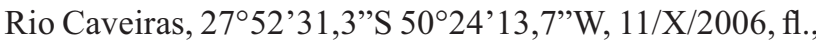
G. B. Ceolin 060 et al. (ICN). São Joaquim, São Francisco Xavier, 1200 m, 4/II/1963, fl., R. Reitz 6674 (HBR). Rio Grande do Sul: Alegrete, Cerro do Tigre, X/1985, fl., $M$. Sobral et al. 4425 (ICN). Bom Jesus, indo para São José dos Ausentes, 06/I/1988, fl., A. Zanin 89 (ICN). Porto Alegre, Morro do Osso, 15/IX/1995, fl., R. S. Rodrigues 356 (ICN). São Francisco de Assis, 19/XII/2000, fl., $S$. T. S. Miotto \& R. L. C. Bortoluzzi 843 (ICN).

Collaea stenophylla é encontrada na Argentina, Uruguai, Paraguai e no sul do Brasil (Burkart 1987). Na
Região Sul, ocorre em praticamente todas as formações vegetais, sendo menos freqüente nas áreas de Floresta Estacional Decidual. Apresenta intensos eventos reprodutivos em quase todos os meses do ano (julho a abril), florescendo e frutificando quase simultaneamente. Além disso, possui um sistema de propagação vegetativa que possibilita uma rápida colonização da área ocupada e a formação de grandes populações. A espécie é polinizada por himenópteros dos gêneros Bombus e Xilocopa (Burkart 1952), além de apresentar muitos pequenos coleópteros, formigas e outros insetos dentro de suas flores, possivelmente devido ao nectário presente na base do ovário. Encontrada a pleno sol, principalmente em barrancos, em campos com solos rasos e pedregosos e em afloramentos rochosos.

\section{Agradecimentos}

Ao CNPq e à CAPES pelas bolsas de Mestrado concedidas ao primeiro Autor e ao CNPq pela Bolsa de Produtividade em Pesquisa concedida à segunda Autora.. A Anelise Scherer e Vagner Cortez pelas ilustrações. A Eduardo Giehl, Ernesto Guarino, Ana Franco e Martin Molz pelos comentários e sugestões. A Raquel Lüdtke, Rafael Trevisan e Ângelo Schneider pela companhia e auxílio nas viagens de coleta.

\section{Referências bibliográficas}

Angely, J. 1965. Flora Analítica do Paraná. Curitiba, Phytos.

Araújo, G.M.; Barbosa, A.A.A.; Amaral, A.F. \& Arantes, A. A. 2002. Composição florística de veredas no Município de Uberlândia, MG. Revista Brasileira de Botânica 25: 475-493.

Barroso, G.M. 1991. Sistemática das Angiospermas do Brasil. v. 2. Viçosa, Editora da Universidade Federal de Viçosa.

Bentham, G. 1859. Collaea. Pp. 144-153. In: K.F. von Martius (eds.). Flora Brasiliensis 15. Monachii, Lipsiae.

Burkart, A. 1943. Las leguminosas argentinas silvestres y cultivadas. Buenos Aires, ACME.

Burkart, A. 1952. Las leguminosas argentinas silvestres y cultivadas. $2^{\text {a }}$ edição. Buenos Aires, ACME.

Burkart, A. 1971. El género Galactia (Leg. Phaseoleae) en Sudamérica con especial referencia a la Argentina y paises vecinos. Darwiniana 16: 663-796.

Burkart, A. 1987. Leguminosae. Pp. 442-743. In: Burkart, A.; Burkart, N.S.T. \& Bacigalupo, N. M. (eds.). Flora Ilustrada de Entre Ríos (Argentina). Tomo VI, parte III. Buenos Aires, Colección Científica del INTA.

Buzato, S.; Sazima, M. \& Sazima, I. 2000. Hummingbird-pollinated floras at three atlantic forest sites. Biotropica 32: 824-841.

Cervi, A.C.; von Linsingen, L.; Hatschbach, G. \& Ribas, O.S. 2007. A vegetação do Parque Estadual de Vila Velha, Município de Ponta Grossa, Paraná, Brasil. Boletim do Museu Botânico Municipal 69: $1-52$.

Fortunato, R.H. 1995. A new species of Collaea (Leguminosae: Papilionoideae: Phaseoleae: Diocleinae) from Brazil. Kew Bulletin 50: 795-799.

Grisebach. A. 1874. Plantae Lorentzianae. Abhandlungen der Königlichen Gesellschaft der Wissenschaften zu Göttingen 19: 77-78.

Hatschbach, G.; Von Linsingen, L.; Uhlmann, A.; Cervi, A.C.; Sonehara, J.S. \& Ribas, O.S. 2005. Levantamento florístico do cerrado (savana) paranaense e vegetação associada. Boletim do Museu Botânico Municipal 66: 1-40.

Holmgren, P.K. \& Holmgren, N.H. 2007. Index Herbariorum on the Internet. Disponível em http://www.nybg.org/bsci/ih.ih.html. (Acessado em: 01/10/2007)

Klein, R. M. 1979. Ecologia da flora e vegetação do Vale do Itajaí. Sellowia 31: $139-140$ 
Lewis, G.P.; Schirire, B.; MacKinder, B. \& Lock, M. 2005. Legumes of the world. Kew, Royal Botanic Gardens.

Lewis, G.P. 1987. Legumes of Bahia. Kew, Royal Botanic Gardens.

Manhães, M.A. 2003. Dieta de Traupíneos (Passeriformes, Emberizidae) no Parque Estadual de Ibitipoca, Minas Gerais, Brasil. Iheringia, Série Zoologia 93: 59-73.

Miotto, S.T.S. 1980. Sistemática das subtribos Cajaninae e Galactiinae (Phaseoleae - Fabaceae) no Rio Grande do Sul. Dissertação (Mestrado em Botânica). Universidade Federal do Rio Grande do Sul, Porto Alegre.

Miotto, S.T.S. 1993. Situação dos estudos taxonômicos da família Leguminosae na região Sul do Brasil. Napaea 9: 5-11.

Morim, M.P. 2006. Leguminosae arbustivas e arbóreas da floresta atlântica do Parque Nacional do Itatiaia, sudeste do Brasil: padrões de distribuição. Rodriguésia 57: 27-45.

Queiroz, L.P.; Fortunato, R.H. \& Giulietti, A.M. 2003. Phylogeny of the Diocleinae (Papilionoideae:Phaseoleae) based on morphological characters. Pp. 303-324. In: B. B. Klitgaard \& A. Bruneau (eds.). Advances in Legume Systematics part 10, Higher Level Systematics. Kew, Royal Botanic Garden.
Rambo, B. 1953. Estudo comparativo das leguminosas riograndenses. Anais Botânicos do Herbário Barbosa Rodrigues 3: 107-184.

Rambo, B. 1966. Leguminosae riograndensis. Pesquisas 23: 1-166.

Reitz, R. 1961. Vegetação da zona marítima de Santa Catarina. Sellowia 13: 17-117.

Silvestre-Capellato, M. \& Melhem, T. S. 1997. Flora polínica da Reserva do Parque Estadual das Fontes do Ipiranga (São Paulo, Brasil). Família 81 - Leguminosae. Hoehnea 24: 119-167.

Takeda, I.J.M. \& Farago, P.V. 2001. Vegetação do Parque Estadual de Vila Velha - guia de campo, v.1. Curitiba, Edição dos autores.

Taubert, P. 1889. Leguminosae novae v. minus cognitae austroamericanae. Flora 72: 421-430. Disponível em: http://www. botanicus.org/item/31753002307384 (acessado em: 10/11/2008).

Taubert, P. 1894. Galactia. Pp. 368. In: A. Engler \& K. Prantl (eds.). Die Natürlichen Pflanzenfamilien 3. Leipzig.

Von Linsingen, L.; Sonehara, J.S.; Uhlmann, A., Cervi, A. 2006. Composição florística do Parque Estadual do Cerrado de Jaguariaíva, Paraná, Brasil. Acta Biologica Paranense 35:197-232. 